\title{
Tiroglossal duktus kistinde gelişen papiller tiroid karsinom
}

Papillary carcinoma arising from thyroglossal duct cyst

\author{
Aykut Bozan ${ }^{1} \quad$ Ayşe Polat $^{2} \quad$ Hayrettin Cengiz Alpay ${ }^{3} \quad$ Sercan Göde ${ }^{4}$ \\ ${ }^{1}$ Medical Park Tarsus Hastanesi, Kulak Burun Boğaz Kliniği, Mersin, Türkiye \\ ${ }^{2}$ Mersin Patoloji Laboratuvarı, Mersin, Türkiye \\ ${ }^{3}$ İstanbul Kemerburgaz Üniversitesi Tıp Fakültesi, Kulak Burun Boğaz Hastalıkları Anabilim Dalı, \\ İstanbul, Türkiye \\ ${ }^{4}$ Ege Üniversitesi Tıp Fakültesi, Kulak Burun Boğaz Hastalıkları Anabilim Dalı, İzmir, Türkiye
}

\section{Öz}

Tiroglossal duktus kisti tiroid glandın dil kökünden boyuna doğru olan embriyolojik göçü sırasında, bu kanalın patent kalmasıyla gelişen konjenital bir kisttir. Bu duktus kistinden malignite gelişme oranı çok düşük olmakla birlikte en sık karşılaşılan malign tümör papiller karsinomdur. Bu yazıda, boyunda orta hatta kitlesi olan ve histopatolojik inceleme sonucu tiroglossal duktus kisti içinden köken alan ve papiller tiroid karsinomu olarak rapor edilen 46 yaşındaki kadın hasta sunulmaktadır.

Anahtar Sözcükler: Tiroglossal duktus kisti, tiroglossal kanal, papiller karsinom.

\begin{abstract}
Thyroglossal duct cyst is a congenital cyst originating from patent duct remnant during embryological migration of thyroid gland from tongue to neck via foramen ceacum. Malignancy arising from this duct is very rare, whereas in case of malignancy, papillary thyroid carcinoma is encountered mostly. In this paper, we report a 46-year-old female patient who referred to our clinic with a midline neck mass whose histopatological evaluation revealed papillary thyroid carcinoma arising from the thyroglossal canal cyst.
\end{abstract}

Keywords: Thyroglossal duct cyst, thyroglossal duct, papillary carcinoma.

\section{Giriş}

Tiroglossal duktus kistleri boyunda en sık karşılaşılan konjenital kitledir. Tiroglossal duktus kistinden karsinom gelişimi nadir olup yaklaşık \%1'inde görülmektedir. Tiroglossal duktus kistinde gelişen karsinomların en sık histolojik tipini papiller tiroid karsinom oluşturmaktadır (1). $\mathrm{Bu}$ yazıda, tiroglossal duktus kisti içinde gelişen papiller tiroid karsinomlu 46 yaşındaki kadın hastayı literatür eşliğinde sunmayı amaçladık.

\section{Olgu Sunumu}

Kırk altı yaşındaki kadın hasta 4 yıldır boyun orta hatta yavaş şekilde büyüyen kitle nedeniyle polikliniğimize başvurdu. Hastanın boyunda kitle dışında ağrı, akıntı, disfaji, dispne, disfoni gibi ek şikayeti yoktu. Yapılan fizik muayenede boyun orta hatta yer alan, vertikal planda tiroid kartilaj seviyesinden submental alana kadar uzanan yaklaşık $5 \times 4.5 \times 3.5 \mathrm{~cm}$ boyutlarında solid, semi-mobil kitle palpe edildi.

Yazışma Adresi: Aykut Bozan

Medical Park Tarsus Hastanesi, Kulak Burun Boğaz Kliniği, Mersin, Türkiye

Makalenin Geliş Tarihi: 11.05.2016 Kabul Tarihi: 14.06.2016
Ağız-boğaz, nazofarinks ve larinks muayenesinde patolojik bulgu saptanmadı. Boyun ultrasonografisi ve tomografisi; tiroid bezinin hemen süperior kesiminde orta hat düzeyinde submental bölgeye uzanan kraniokaudal boyutu $60 \mathrm{~mm}$, aksiyel boyutları 44x31 mm olan, kalın septasyonlar, posterior duvarında ve septalarda kalsifikasyonlar barındıran kalın duvarlı yoğun içerikli kistik lezyon (komplike tiroglossal kist?) olarak rapor edildi (Şekil-1A). Kitleden ince iğne aspirasyon biyopsisi yapıldı ve seröz mayi aspire edildi. Biyopsi sonucu benign kist içeriği olarak rapor edilmesi üzerine tiroglossal duktus kisti ön tanısı ile operasyon planlandı. Preoperatif tiroid fonksiyon testleri normal bulunan hastaya genel anestezi altında Sistrunk operasyonu yapıldı. Operasyonda kistik kitle; traktusu, hyoid kemik korpusu ile birlikte en-bloc rezeke edildi. Peroperatif ve postoperatif komplikasyon gelişmedi.

\section{Patolojik Inceleme}

Makroskopik incelemede kesit yüzeyinde lümenleri kirli sarı renkte mayi ile dolu multiloküler kistik yapılar saptandı, bir alanda $1 \mathrm{~cm}$ çapta lümene doğru uzanan papiller yapı izlendi (Şekil-1B). Materyalden hazırlanan kesitlerin histopatolojik incelenmesinde; geniş alanda 
döşeyici epiteli izlenmeyen, duvarında inflamatuar hücreler ve taze kanama odakları içeren multiloküle kistik yapının duvarında tiroid parankim dokusu ve bu alanda ince fibrovasküler stromaya tutunmuş tek sıralı, nükleusları yer yer buzlu cam görünümünde, eosinofilik sitoplazmalı atipik tirositlerin oluşturduğu papiller yapılar izlendi (Şekil-1C,1D). Ayrıca tümör hücrelerinin bir kısmında konsantrik kalsiyum birikimleri (psammom cisimleri) görüldü. Mikroskopik tanı tiroglossal kist duvarından gelişen papiller karsinom olarak rapor edildi. Tümör çapı $1 \mathrm{~cm}$ ve kist duvarına $2 \mathrm{~mm}$ uzaklıkta idi. Kistin dış yüzeyinde serbest tümör ve lenfovasküler invazyon yoktu.

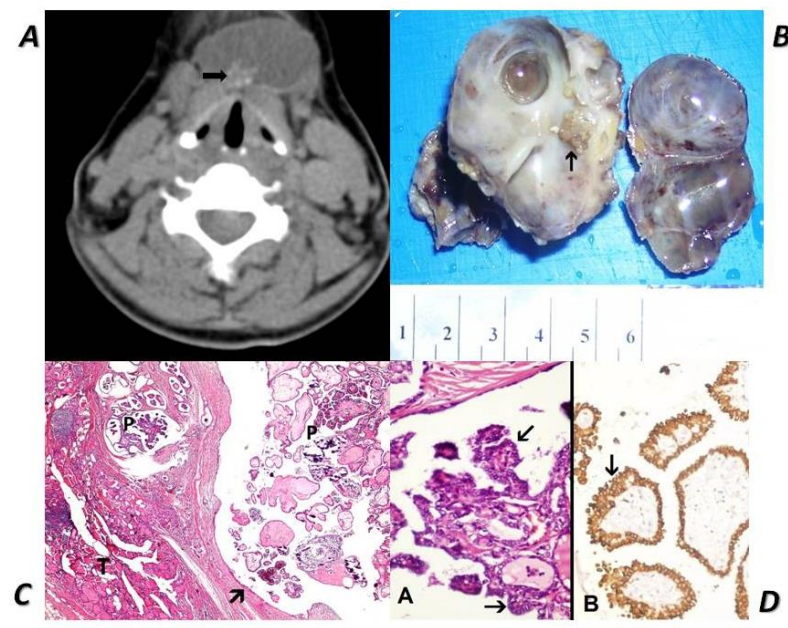

Şekil-1. A. Boyun BT'de kalsifikasyon gösteren (ok ile işaretli) yoğun içerikli kistik kitle. B. Tiroglossal kist duvarında $1 \mathrm{~cm}$ çapında papillomatöz kitle (ok ile işaretli). C. Lümeni kısmen nonkeratnize skuamöz epitelyum ile döşeli (ok ile işaretli) tiroglossal kist duvarında tiroid dokusu $(\mathrm{T})$ içerisinde, ince fibrovasküler stromaya tutunmuş tek sırali, nükleusları buzlu cam görünümünde, atipik tirositlerin oluşturduğu papiller yapılar $(P)$. Tümör lümen içerisine de papiller tarzda gelişim göstermektedir. D. Buzlu cam görünümündeki tümör hücrelerinin daha yakından görünümü (ok ile işaretli) $(A)$. Galektin 3 ile tümör hücrelerinde güçlü pozitif boyanma (ok ile işaretli) izlenmektedir ( $B$ ).

Hastaya postoperatif 1.ayda yapılan tiroid sintigrafisinde ve tiroid ultrasonografisinde patolojik lezyon izlenmedi. Tiroid fonksiyon testleri normal sınırlardaydı. Papiller karsinomun primer olduğu düşünüldü. Tiroid süpresyon tedavisi başlandı. Tiroidektomi yerine hastaya 2 ayda bir tiroid ve boyun ultrasonografisi, 6 ayda bir tiroid sintigrafisi ve boyun MR ile değerlendirilmesi kararlaştırıldı. Hasta postoperatif 9 . ayda halen sağ olup, kontrollerinde nüks bulgusuna rastlanmamıştır.

Hastadan tıbbi verilerinin yayınlanabileceğine ilişkin yazılı onam belgesi alındı.

\section{Tartışma}

Tiroglossal duktus, tiroid bezi ile foramen çekum arasındaki epiteliyal bağlantıdır. Normalde duktus gestasyonun 8 ila 10. haftasında involüsyona uğrar.
Duktus involüsyonu gerçekleşmez ise epiteliyal artıklar ve sekresyonlar duktus içerisinde birikerek kist oluşumuna yol açar. Duktus kaybolmayıp, içerisine olan sekresyonlar ile kist oluşabilmektedir. Tiroglossal duktus kistlerinin hepsi orta hattadır. \%50'si hyoidin inferiorunda yerleşir (2). Olgumuzda kitlenin büyük boyutlarda olması nedeniyle hem suprahyoid, hem de infrahyoid bölgede yerleşmiştir.

Tiroid papiller kanserler tiroglossal kanal kistlerinde gelişen en sık malign tümörleridir. Diğerleri skuamöz hücreli karsinom ve adenoskuamöz karsinomdur (2). Papiller kanserler daha çok lokal-bölgesel olarak yayılan, nadir uzak metastaz yapan tümörlerdir (3).

Tiroglossal kistinden gelişen papiller karsinom adolesan ve erişkin kadınlarda daha sık görülür (3) Olgumuz 46 yaşında kadın idi. Klinik olarak hastalarda ağrı, ses kısıklığı, kist boyutlarında ani artış, boyunda lenfadenopati bulgularının olması malign bir kitleyi düşündürür (4), ancak olgumuzda maligniteyi düşündüren bir belirti ve bulgu yoktu.

Tiroglossal duktus kistinden papiller karsinom gelişimi etiyolojisi iki farklı teori ile açıklanmaktadır (5). Birinci teoriye göre, kist duvarındaki ektopik tiroid dokusundan de novo olarak karsinomun geliştiği ileri sürülmektedir. İkinci teoride ise karsinomun tiroid dokusundan tiroglossal duktus yoluyla yayıldığı düşünülmektedir. Tiroglossal duktus kistinde gelişen papiller karsinomun primer olması için gerekli kriterler; Kist epitel duvarının olması, kistin içinde veya yakınında normal tiroid dokusunun bulunması, tiroid bezinde primer tümör varlığının gösterilmemesi ve tiroid bezinin klinik olarak normal olmasıdır (6). Olgumuzda da kist epitelinin olması, kist duvarında normal tiroid dokusunun bulunması ve tiroid bezinin klinik ve radyolojik olarak normal olması papiller karsinomun primer olduğunu gösteren bulgulardır.

Preoperatif bilgisayarlı tomografide kist içinde kalsifikasyon bulguları, benign tiroglossal duktus kistinden ayırıcı tanısında önemlidir (7). Olgumuzda preoperatif bilgisayarlı tomografide kistin posterior duvarında kalsifikasyon odağı izlenmiştir.

Tiroglossal duktus kisti zemininde papiller tiroid karsinom tanısı kesinleşen vakalarda tiroid gland radyolojik ve sintigrafik olarak değerlendirilmelidir (8). Tiroglossal duktus kistinden kaynaklanan papiller karsinom tedavisinde kist duvarını aşan tümör invazyonu veya servikal lenf nodlarına yayılım bulunmadığı, tiroid bezinin normal olduğu, tümör çapının $1 \mathrm{~cm}$ 'den büyük olmadığı durumlarda Sistrunk işlemi ve postoperatif tiroid süpresyon tedavisi önerilmektedir (9). Bu kriterlere uymayan tümör varlığında, boyunda lenf nodu tutulumu veya kist duvarı invazyon durumunda tiroidektomi ile beraber modifiye radikal boyun diseksiyonu uygulanması gerekmektedir (10). Olgumuzda tümör çapı $1 \mathrm{~cm}$ idi. Kist duvarı invazyonu ve lenf nodlarına yayılım yoktu. Tiroid bezinin ultrasonografik ve sintigrafik olarak 
değerlendirilmesinde normal olduğu izlendi. Bu nedenle Sistrunk operasyonu yeterli görüldü, tiroid süpresyon tedavisi başlandı ve hasta yakın takibe alındı. Ancak tümörün primer olmadığı durumlarda, invazyon varlığında veya multisentrik tümör olabileceğine yönelik klinik bulgu varsa Sistrunk operasyonuna ilaveten tiroidektomi ve/veya boyun diseksiyonu yapılması gerekir.

\section{Kaynaklar}

1. Balalaa N, Megahed M, Ashari MA, Branicki F. Thyroglossal duct cyst papillary carcinoma. Case Rep Oncol 2011;4(1):39-43.

2. Proia G, Bianciardi Valassina MF, Palmeieri G, Zama M. Papillary carcinoma on a thyroglossal duct cyst: Diagnostic problems and therapeutic dilemma. A case report. Acta Otorhinolaryngol Ital 2014;34(3):215-7.

3. Martins AS, Melo GM, Tincani AJ, Lage HT, Matos PS. Papillary carcinoma in thyroglossal duct: Case report. Sao Paulo Med J $1999 ; 117(6): 248-50$

4. Wigle TL, Chonkich GD, Wat BY. Papillary duct carcinoma arising in a thyroglossal duct cyst. Otolaryngol Head Neck Surg 1997;116(3):386-8.

5. Yang S, Park KK, Kim JH. Papillary carcinoma arising from throglossal duct cyst with thyroid and lateral neck metastasis. Int $\mathrm{J}$ Surg Case Rep 2013;4(8):704-7.

6. Samara C, Bechrakis I, Kavadias S, Papadopoulos A, Maniatis V, Strigaris K. Thyroglossal duct cyst carcinoma. Neuroradiology 2001;43(8):647-9.

7. Branstetter BF, Wiessman JL, Kennedy TL, Whitaker M. The CT appearance of thyroglossal duct carcinoma. Ann J Neuroradiol 2000;21(1):1547-50

8. Luna-Ortiz K, Hurtado-Lopez LM, Valderrama-Landaeta L, Ruiz-Vega A. Thyroglossal duct cyst with papillary carcinoma: What must be done? Thyroid 2004;14(5):363-6.

9. Heshmati HM, Fatourechi V, van Heerden JA, Hay ID, Goellner JR. Thyroglossal duct carcinoma: Report of 12 cases. Mayo Clin Proc 1997;72(4):315-9.

10. Maleki N, Alamdari MN, Feizi F, Tavosi Z. Papillary carcinoma of the thyroglossal duct cyst: Case Report. Iran J Public Health 2014;43(4): 529-31. 